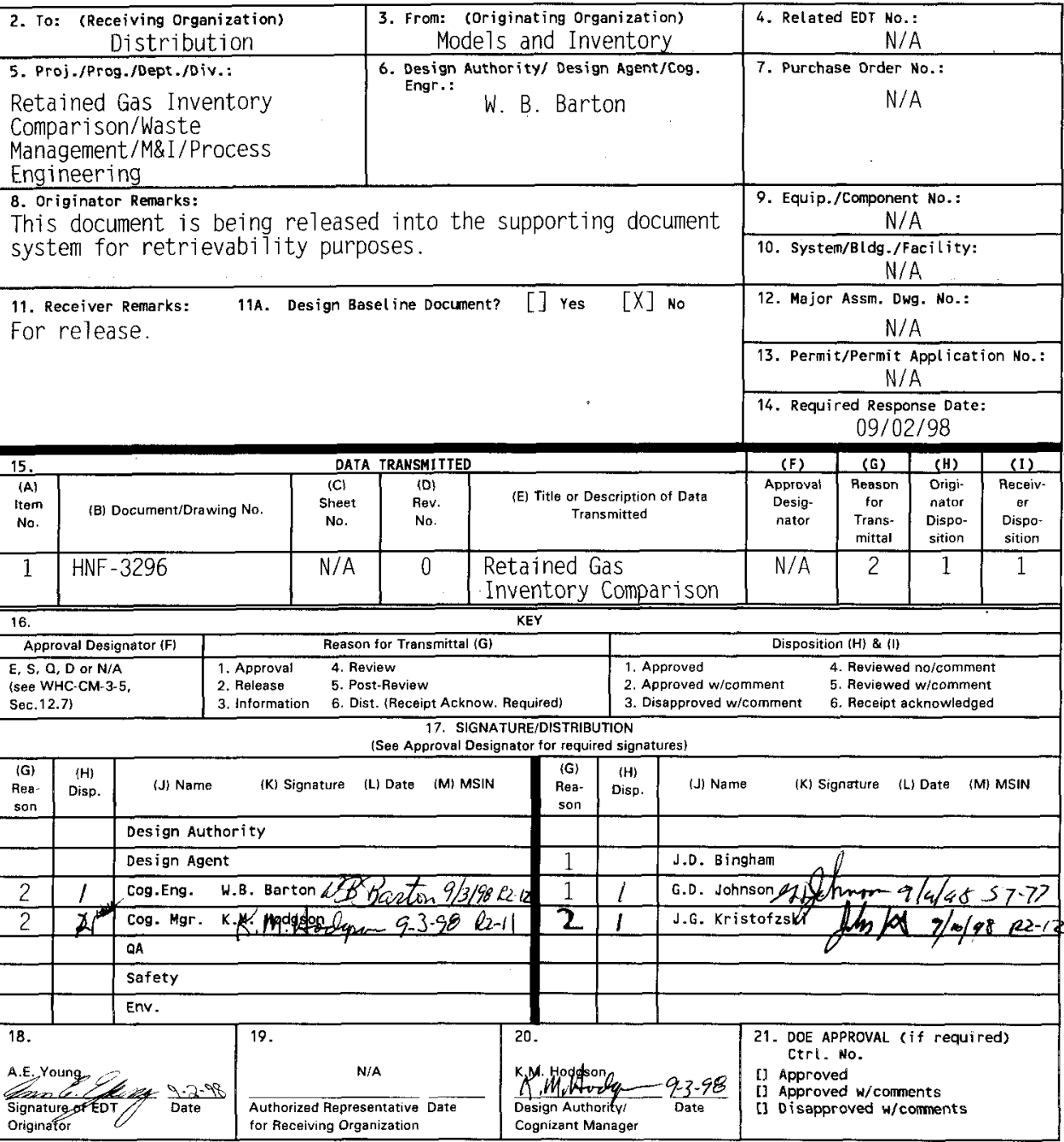

BD-7400-172-2 (05/96) GEF097 


\title{
Retained Gas Inventory Comparison
}

\author{
W. B. Barton \\ Lockheed Mart in Hanford, Corp., Richland, WA 99352 \\ U.S. Department of Energy Contract DE-AC06-96RL 13200
}

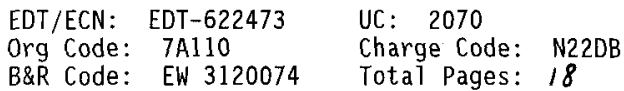

Key Words: Basis for Interim Operations, (BI0), Surface Level Rise, SLR, Barometric Pressure Effect, (BPE), Void Fraction Instrument, (VFI), Retained Gas SampTer, (RGS).

Abstract: Gas volume data derived from four different analytical methods were collected and analyzed for comparison to volumes originally used in the technical basis for the Basis for Interim Operations (BIO). The original volumes came from Hodgson (1996) listed in the reference section of this document. Hodgson (1996) screened all 177 single and double-shell tanks for the presence of trapped gas in waste via two analytical methods: Surface Level Rise (SLR), and Barometric Pressure Effect (BPE). More recent gas volume projections have been calculated using different analytical techniques along with updates to the parameters used as input to the SLR and BPE models. Gas volumes derived from new analytical instruments include those as measured by the Void Fraction Instrument (VFI) and Retained Gas Sampler (RGS). The results of this comparison demonstrate that the original retained gas volumes of Hodgson (1996) used as a technical basis in developing the BIO were conservative, and were conservative from a safety analysis standpoint. These results represent only comparisons to the original reported volumes using the limited set of newly acquired data that is available.

TRADEMARK DISCLAIMER. Reference herein to any specific comercial product, process, or service by trade name, trademark, manufacturer, or otherwise, does not necessarily constitute or imply its endorsement, recommendation, or favoring by the United States Governinent or any agency thereof or its contractors or subcontractors.

Printed in the United States of America. To obtain copies of this document, contact: Document Control Services, P.O. Box 950, Mailstop H6-08, Richland WA 99352, Phone (509) 372-2420; Fax (509) 376-4989.

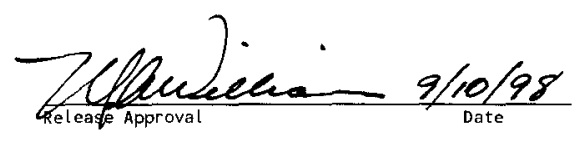

Approved for Public Release 
HNF-3296

Revision 0

\section{Retained Gas Inventory Comparison}

J. D. Bingham

W. B. Barton

Lockheed Martin Hanford Corp.

Date Published

September 1998

Prepared for the U.S. Department of Energy

MUOR DANIE HANFOR, UNe
P.O. Box 1000

Richland, Washington

Hanford Management and Integration Contractor for the

U.S. Department of Energy under Contract DE-AC 06-96RL 13200 
HNF-3296, Rev. 0

\section{RETAINED GAS INVENTORY COMPARISON}

\section{SUMMARY}

Gas volume data derived from four different analytical methods were collected and analyzed for comparison to volumes originally used in the technical basis for the Basis for Interim Operations (BIO). The original volumes came from Hodgson (1996). Hodgson (1996) screened all 177 single and double-shell tanks for the presence of trapped gas in the waste via two analytical methods. One method was Surface Level Rise (SLR), which calculates the volume of gas stored in the waste based on observed net changes in surface level, while the second was the Barometric Pressure Effect (BPE), which calculates stored gas volumes based on the magnitude of changes in measured surface level due to changes in atmospheric pressure.

More recent gas volume projections have been calculated using different analytical techniques along with updates to the parameters used as input to the SLR and BPE models described above. Gas volumes derived from new analytical instruments include those as measured by the Void Fraction Instrument (VFI) and Retained Gas Sampler (RGS).

The results of this comparison demonstrate that the original retained gas volumes of Hodgson (1996) used as a technical basis in developing the BIO were suitable, and were conservative from a safety analysis standpoint.

These results represent only comparisons to the original reported volumes using the limited set of newly acquired data that is available.

\section{PURPOSE}

The purpose of this comparison study is to determine whether the retained gas volumes originally used in the BIO are significantly different than those estimated from recent data. The methods used for comparison of the reported gas volumes are also discussed.

\section{INTRODUCTION}

This document compares gas volume data derived from four different analytical methods to volumes originally used in the technical basis of the Justification for Continued Operation (JCO) (flammable gas safety controls implementation document). The JCO is found as Appendix E of the BIO (Leach, 1997). This document serves as a statement of the applicability of the original gas volumes used in the BIO. 
HNF-3296, Rev. 0

The original retained gas volume estimates used as the technical basis came from Hodgson (1996). Hodgson (1996) screened all 177 single and double-shell tanks for the presence of trapped gas in the waste via two analytical methods. One method was the SLR, which calculates the volume of gas stored in the waste based on observed net changes in surface level, while the second method was the BPE, which calculates stored gas volumes based on the magnitude of changes in measured surface level due to changes in atmospheric pressure (dl/dp). Hodgson (1996) utilized these methods to screen tanks that would likely cause their associated headspace flammable gas concentrations to exceed $25 \%$ of the lower flammability limit (LFL) if a significant fraction of their gas inventories was released from the waste.

Since Hodgson (1996) was published, different estimates of retained gas volumes have become available from new analytical techniques along with updates to the parameters used as input to the SLR and BPE models. The updates utilize more recent data, which are often considered to be of higher quality. Additionally, reevaluations were performed correcting discrepancies in the original evaluations.

Gas volumes derived from new analytical instruments include those as measured by the VFI and RGS. These measurements are available for a limited number of tanks, but have the advantage of directly measuring the tank waste conditions present at the time of the measurement or sampling event.

The VFI is designed to measure the volume fraction of free gas at specific locations in a tank. It is deployed directly into the waste to a desired elevation through a tank dome riser. The VFI is lowered through the waste with an open sampling chamber, allowing undisturbed waste to fill the chamber. The sampling chamber is located at the end of a horizontal arm (the arm is vertically positioned when deployed through the tank riser). At the measurement location, the sampling chamber cover is closed to capture a sample. The waste is then compressed in the sampling chamber using nitrogen gas through a connecting line. The void fraction is then calculated from the measured initial and final pressures along with known system temperatures and volumes (Stewart, 1996). The instrument is capable of providing multiple void measurements in the waste at a particular elevation due to the fact that the horizontal arm can be rotated in a circular manner about the riser centerline in the waste. These measured void fractions are then averaged and used to calculate a stored gas volume for a region of waste in the tank; thereby the entire tank gas inventory can be derived.

The RGS is a modified segment from a core sample. During a core sampling effort, specific segments are selected for RGS sampling based on desired locations in the waste. When the segment containing the sampler is deployed to the applicable location in the waste, a valve is opened that allows waste to be collected by the RGS. The valve is then closed, creating a gastight seal to the RGS. After the RGS core segment is retrieved, the sampler is subjected to $\mathrm{X}$-rays to estimate the void fraction at the sample elevation. The off gasses from the waste are drawn from the RGS for analysis by vacuum. As was done for the VFI, the void fractions are then integrated over the entire tank contents to derive a total gas volume inventory for the tank. 
HNF-3296, Rev. 0

In addition to the VFI and RGS data that have become available since the issuance of the BIO, a revised BPE model has been developed and additional high quality tank data have been obtained. As better waste level data became available, it was found that the original ideal gas law model was not adequate to describe the waste behavior in some of the tanks. In particular, comparisons of tank waste level data with atmospheric pressure did not show simple linear behavior as would be predicted by the gas law model. Whitney (1997) developed a refined model utilizing surface level data from tanks with $\mathrm{ENRAF}^{\prime}$ level gauges connected to the Tank Monitoring and Control System (TMACS) data acquisition system. This refined model estimates $\mathrm{dl} / \mathrm{dp}$ based on a "linear parallelogram estimation" method (BPE II) and is considered to be more accurate than the gas law model; the tank data used as inputs to the model are of higher quality because of more frequent and precise instrumentation measurements.

Whitney (1997) published new dl/dp estimates for 52 tanks. The median values from these new estimates were analyzed using the same methodology (Hopkins, 1996) employed in Hodgson (1996) to calculate retained gas volumes. These new BPE II gas volumes have been included in this document for comparison to the previously reported retained gas volumes (Hodgson, 1996).

\section{METHODOLOGY}

The first step taken was the collection of the original data from Hodgson (1996) used as the technical basis for the JCO. This was obtained from an electronic spreadsheet summary file maintained by Tank Waste Remediation System (TWRS) Process Engineering that tracks the inputs and results of each tank's flammable gas evaluation as reported in Hodgson (1996). Specific data extracted included the volume of trapped gas in the waste from both evaluation methods; the SLR and BPE models.

Hodgson (1996) initially screened all 177 tanks for the presence of trapped gas based upon a tank's current surface level and several enabling assumptions. It is considered to be very conservative. The screening evaluated the tanks assuming they had the gas generating characteristics of tank 241-SY-101. All tanks were evaluated on a pass/fail basis whether the potential existed to exceed $25 \%$ of the LFL of the vapor space. This "quick screen" removed 55 tanks from the SLR and BPE evaluation. However, 3 tanks out of the 55 were still evaluated, and their results included in the original gas volume inventory. The remaining 122 tanks were then screened for applicability to the BPE model by analyzing their surface level histories for correlations with atmospheric pressure swings. If a tank was found to have a correlation with atmospheric pressure, then the BPE model evaluation was performed. All of the 122 tanks that did not pass the quick screen were evaluated for gas volumes based on the SLR model.

One parameter that has been identified as a possible indicator of trapped gas is an increase in the waste surface level. A surface level rise can result from other factors besides trapped gas (for

\footnotetext{
1 Trademark of the ENRAF-NONIUS B.V. Corporation
} 
HNF-3296, Rev. 0

example, rainwater intrusion), but the Hodgson (1996) evaluation assumed it resulted from trapped gas. These rises in surface level are used to estimate the volume of retained gas via the calculations contained in the SLR model.

The SLR model assumes that the rate of change in waste surface level is a result of gas accumulation in addition to liquid evaporation, waste addition, leakage, density changes, and waste surface structural changes (subsidence). It does not require exceptionally accurate or frequent level measurements or any knowledge about the vertical distribution of gas to estimate the retained gas volume. The minimum number of waste level measurements needed to qualitatively assess the presence of retained gas are approximately six to twelve values over a period of six to twelve months. However, it is subject to the uncertainties associated with water evaporation or condensation, waste transfers to or from the tank, and structural changes in the waste surface (Meyer, 1997).

In practice, the SLR model can be used to 1) identify the probability that a tank is accumulating gas and 2) in limited cases to provide estimates of the quantity of gas retained in the waste. In the second case applying the concept can be challenging because of the long time period, potential correction terms, etc. As a result, SLR is best used as a qualitative indicator of trapped gas.

Since the time of the original evaluations, tanks have been reevaluated using the methodology found in Hopkins (1996) for trapped gas volumes. Reasons for this include:

- New/more data became available

- Tank specific parameters that were input into either of the models changed

- Errors were found in the original evaluations

- Certain evaluations did not account for evaporation of the tank waste

- The tanks that had passed the quick screen were subsequently evaluated using the SLR and BPE

Tanks that were reevaluated are included in this report for comparison to the retained gas volumes found in Hodgson (1996). The criteria used in selecting the tanks included that a tank had to have a BPE reevaluation performed. However, if a reevaluated tank also had additional retained gas volume estimate data, either directly (VFI or RGS) measured or derived from the BPE II model, its' reevaluated volumes were also included in Table 1 for comparison. The results from reevaluating the tanks reside within the TWRS Process Engineering electronic spreadsheet summary file (see Appendix for a table of data inputs and evaluation results adapted from the spreadsheet summary file), with the exception of tanks 241-BY-109, 241-T-110, and 241-BY-103, which are found as Revision 1A, 1B, and 1C to Hodgson (1996) respectively (these revisions were used to facilitate changing the flammable gas facility group designations for these tanks from Facility Group 2 to Facility Group 3). Eight tanks that were reevaluated had 


\section{HNF-3296, Rev. 0}

originally passed the quick screen evaluation. Their results are included in this report for comparison to retained gas volume estimates derived using the BPE II model. The retained gas volume estimates obtained from the reevaluations are referred to in this document together as "Reevaluations".

VFI and RGS data were also collected for comparison. As mentioned earlier, the data derived from these methods offer the advantage of being directly measured in the waste, but the number of tanks analyzed are limited.

The source for the VFI derived total gas volumes is Stewart (1996) for the non-convective and convective layers, and Meyer (1997) for the crust layer volume. These VFI volumes apply to double-shell tanks (DSTs) 241-AN-103, 241-AN-104, 241-AN-105, 241-AW-101, 241-SY-101, and 241-SY-103.

The source for the RGS derived total gas volumes pertaining to DSTs is Shekarriz (1997). For tanks 241-AN-104, 241-AN-105, and 241-AW-101, the total volumes are summed from RGS data for the non-convective and convective layers, and Meyer (1997) provides the crust layer gas volumes. RGS data for single shell tanks were taken from Mahoney (1997) for tanks 24I-BY-109, 241-S-106 and 241-U-103 and from Shekarriz (1997) for tank 241-A-101.

Total gas volume estimates were also obtained from Meyer (1997) for comparison. Meyer (1997) summarized available gas volume data and refined the models used in the prior documents (Stewart, 1996 and Shekarriz, 1997) for DSTs. Meyer reported gas volumes for tanks 241-AN-103, 241-AN-104, 241-AN-105, 241-AW-101, 241-SY-101 and 241-SY-103. RGS data were used in combination with VFI data to determine gas volumes for all of these tanks with the exception of tank 241-SY-101 and tank 241-SY-103, which only have VFI data associated with them.

The last source of data used in the comparison was that from the BPE II model published by Whitney (1997) for 52 tanks. The BPE II model can be used at any time without existing knowledge of the retained gas volume. It requires sensitive and frequent waste surface level measurements over some period of time to determine the retained gas volume accurately.

In either of the BPE evaluations, it is important to understand the precision of repeated measurements. The precision/repeatability of the measuring device determines the minimum sensitivity in detecting and the standard deviation in estimating retained gas volumes using the BPE method. The various level measuring devices in use at Hanford do not have the same precision. The ENRAF gauge used exclusively in the BPE II model has a higher accuracy and associated repeatability than other level measuring instruments that were used in the original BPE model. High-frequency high-resolution surface level data provide the information needed 
HNF-3296, Rev. 0

to perform the revised evaluation. The precision afforded by the ENRAF gauge is clearly required for reasonably accurate BPE retained gas volume estimations (Meyer, 1997).

Median $\mathrm{dl} / \mathrm{dp}$ values from Whitney (1997) using the BPE II model were input into the same spreadsheet from Hopkins (1996) to calculate retained gas volumes for comparison to what Hodgson (1996) reported. Because of more recent, frequent and precise instrumentation measurements, the BPE II model is considered to be more accurate than the original BPE model. Retained gas volumes derived using median $\mathrm{dl} / \mathrm{dp}$ values from the BPE II model provide a "best estimate". These estimates are most accurate for tanks that have a moderately large volume of waste with a liquid waste surface at the region of level measurement, along with the condition of not having a multitude of suspended equipment penetrating the waste (Meyer, 1997). No formal attempt was made to screen the tanks (in this manner for applicability) that Whitney (1997) published $\mathrm{dl} / \mathrm{dp}$ estimates for. It is believed that the $\mathrm{dl} / \mathrm{dp}$ values yielded retained gas volume estimates that are sufficiently valid within the uncertainties discussed in the Results section.

It should be emphasized that data from the direct sampling tools (RGS and VFI) and volumes derived using median $\mathrm{dl} / \mathrm{dp}$ values from the BPE II model provide retained gas volume estimates, while Hodgson (1996) was developed to provide bounding cases per the approved methodology at that time (Hopkins, 1996).

Qualitative comparisons between tanks are discussed in the following results section for those that have more than one type of gas volume estimate.

\section{RESULTS}

Table 1 lists 65 tanks which have new retained gas volume estimates available for comparison. The two columns labeled Hodgson (1996) represent gas volumes that were used for the technical basis of the BIO.

Perhaps the most instructive way to look at these data is to ask, "Would the new data indicate a change to a more restrictive Facility Group classification for a tank?" With the exception of tank 241-AX-101, none of the changes identified in Table 1 would result in a change from "pass" to "fail" in the outcome of the evaluation found in Hodgson (1996). Thus, since the Facility Group classification is largely based on Hodgson (1996) no change to a more restrictive Facility Group would result. Conversely, re-assessment of the data has resulted in changing tanks 241-T-110, 241-BY-103, and 241-BY-109 from Facility Group 2 to Facility Group 3. Tank 241-AX-101 has an Unreviewed Safety Question (USQ) declared against it based on preliminary results of RGS sampling (Barker, 1998). This tank has been reevaluated to have an gas inventory such that the result in Hodgson (1996) will change from "pass" to "fail" when it is revised.

When the work documented in Hodgson (1996) was performed, the result which gave the largest retained gas estimate controlled the outcome of the evaluation. Inspection of Table 1 shows that 
the methods often give widely different results for the same tank. This highlights the need to carefully reconcile the information about a tank and use multiple methods to assure that the analysis results in a "best estimate" of gas volumes.

All the methods for measuring volume of gas retained in a tank have significant uncertainty associated with them. Although two or three digits are reported, gas volumes are rarely measured more accurately than the nearest 25 cubic meters. Thus, when comparing inventory estimates, variations of this magnitude are not significant.

Table 1. Retained Gas Volume Inventory Comparisons (3 Sheets)

\begin{tabular}{|c|c|c|c|c|c|c|c|c|c|}
\hline \multirow{3}{*}{$\begin{array}{r}\text { Tank } \\
(241-)\end{array}$} & \multicolumn{2}{|c|}{$\begin{array}{c}\text { Hodgson } \\
(1996)\end{array}$} & \multicolumn{2}{|c|}{$\begin{array}{l}\text { Reevaluations } \\
\text { (Appendix) }\end{array}$} & VFI & \multicolumn{3}{|c|}{ RGS } & \multirow{2}{*}{$\begin{array}{c}\text { BPE II } \\
\text { Whitney } 97 \\
\text { (Median dl/dp) }\end{array}$} \\
\hline & $\begin{array}{c}\text { Surface } \\
\text { Level Rise }\end{array}$ & BPE & $\begin{array}{l}\text { Surface } \\
\text { Level Risc }\end{array}$ & BPE & \begin{tabular}{|c|} 
Stewart \\
$96^{1}$
\end{tabular} & $\begin{array}{l}\text { Meyer } \\
97^{2}\end{array}$ & $\begin{array}{c}\text { Mahoney } \\
97\end{array}$ & $\begin{array}{c}\text { Shekarriz } \\
97^{3}\end{array}$ & \\
\hline & $\begin{array}{c}\text { Standird } \\
\text { Volume } \\
\left(\mathrm{m}^{3}\right)\end{array}$ & \begin{tabular}{|c|} 
Standard \\
Volume \\
$\left(\mathbf{m}^{3}\right)$
\end{tabular} & $\begin{array}{c}\text { Standard } \\
\text { Volume } \\
\left(\mathbf{m}^{3}\right)\end{array}$ & \begin{tabular}{|c} 
Standard \\
Volume \\
$\left(\mathrm{m}^{3}\right)$
\end{tabular} & $\begin{array}{c}\text { Standard } \\
\text { Volume } \\
\left(\mathrm{m}^{3}\right)\end{array}$ & $\begin{array}{c}\text { Standard } \\
\text { Volume } \\
\left(\mathrm{m}^{\prime}\right)\end{array}$ & $\begin{array}{c}\text { Standard } \\
\text { Volurne } \\
\left(\mathrm{m}^{3}\right)\end{array}$ & $\begin{array}{c}\text { Standard } \\
\text { Volume } \\
\left(\mathrm{m}^{3}\right)\end{array}$ & $\begin{array}{c}\text { Standard } \\
\text { Volume } \\
\left(\mathrm{m}^{3}\right)\end{array}$ \\
\hline$A-101$ & 2 & 782 & & & & & & 302 & \\
\hline $\mathrm{AN}-103$ & 954 & 854 & & & 464 & 380 & & 281 & 927 \\
\hline$\Lambda \mathrm{N}-104$ & 1127 & 527 & 2154 & 453 & 247 & 236 & & 229 & 344 \\
\hline$A N-105$ & 1318 & 695 & 1096 & 481 & 184 & 189 & & 180 & 367 \\
\hline AW-101 & 397 & 400 & & & 209 & 141 & & 126 & \\
\hline$A W-103$ & 33 & 99 & 33 & 99 & & & & & \\
\hline AW-104. & 219 & 231 & 2.31 & 273 & & & & & \\
\hline$A X-101$ & $\mathrm{BDL}$ & & 60 & & & & $340^{* *}$ & & \\
\hline $13 \times-101 *$ & & & 105 & & & & & & 4 \\
\hline BX-102* & & & 78 & & & & & & BDI. \\
\hline BX-103* & & & 143 & & & & & & BIDL, \\
\hline BX-104: & 71 & 81 & 61 & 81 & & & i & & 32 \\
\hline BX-106* & & & 44 & & & & & & BDI, \\
\hline $\mathrm{BX} \cdot 107$ & 9 & 190 & & & & & & & 60 \\
\hline $\mathrm{BX}-108^{*}$ & & & 77 & & & & & . & $\mathrm{BDL}$ \\
\hline $13 X-109$ & $\mathrm{BDL}$ & & & & & & & & BDI, \\
\hline $3 X-110$ & 42 & & 50 & & & & & & 61 \\
\hline $13 \mathrm{X}-111$. & 31 & & & & & & & & BDL \\
\hline $13 X-112$. & 9 & 63 & 45 & 63 & & & & & $\mathrm{BDL}$ \\
\hline BYY-103. & $\mathrm{BDL}$ & 106 & $\mathrm{BIL}$ & BDL & & & : & & . \\
\hline $13 \mathrm{Y}-109$ & BDL & 121 & BDL & 50 & & & 140 & & \\
\hline$c-103$ & 35 & & BDS. & & & & & & $B D L$ \\
\hline$C^{C}-107$ & BDI & 15 & BDl & 15 & & & & & 9 \\
\hline$S-103$ & 265 & 336 & & & & & & & 208 \\
\hline$s-106$ & 672 & 808 & & & & & 230 & & 698 \\
\hline S- 107 & 570 & 136 & & & & & & & 86 \\
\hline
\end{tabular}


HNF-3296, Rev. 0

Table 1. Retained Gas Volume Inventory Comparisons (3 Sheets)

\begin{tabular}{|c|c|c|c|c|c|c|c|c|c|}
\hline \multirow{3}{*}{$\begin{array}{c}\text { Tank } \\
(241-)\end{array}$} & \multicolumn{2}{|c|}{$\begin{array}{l}\text { Todgson } \\
\text { (1996) }\end{array}$} & \multicolumn{2}{|c|}{$\begin{array}{l}\text { Reevaluations } \\
\text { (Appendix) }\end{array}$} & \multirow{2}{*}{$\begin{array}{c}\text { VFI } \\
\text { Stewart } \\
96^{1}\end{array}$} & \multicolumn{3}{|c|}{ RGS } & \multirow{2}{*}{$\begin{array}{r}\text { BPE II } \\
\text { Whitney } 97 \\
\text { (Median dl/dp) }\end{array}$} \\
\hline & $\begin{array}{l}\text { Surface } \\
\text { Level Rise }\end{array}$ & BPE & $\begin{array}{c}\text { Surface } \\
\text { Level Rise }\end{array}$ & BPE & & $\begin{array}{l}\text { Meyer } \\
97^{2}\end{array}$ & $\begin{array}{c}\text { Mahoney } \\
97\end{array}$ & $\mid \begin{array}{c}\text { Shekarriz } \\
97^{3}\end{array}$ & \\
\hline & $\begin{array}{c}\text { Standard } \\
\text { Volume } \\
\left(\pi^{3}\right)\end{array}$ & $\begin{array}{c}\text { Standard } \\
\text { Volume } \\
\left(\mathrm{m}^{3}\right)\end{array}$ & $\begin{array}{c}\text { Standäd } \\
\text { Volume } \\
\left(\mathrm{m}^{3}\right)\end{array}$ & $\begin{array}{c}\text { Standard } \\
\text { Volume } \\
\left(\mathrm{m}^{3}\right)\end{array}$ & $\begin{array}{c}\text { Standard } \\
\text { Volume } \\
\left(\mathrm{m}^{3}\right)\end{array}$ & $\begin{array}{c}\text { Standard } \\
\text { Volume } \\
\left(\mathrm{m}^{3}\right)\end{array}$ & $\begin{array}{l}\text { Standard } \\
\text { Volume } \\
\left(\mathrm{m}^{3}\right)\end{array}$ & $\begin{array}{c}\text { Standard } \\
\text { Volume } \\
\left(\mathrm{m}^{\prime}\right)\end{array}$ & $\begin{array}{l}\text { Standard } \\
\text { Volume } \\
\left(\mathrm{m}^{3}\right)\end{array}$ \\
\hline$S-111$ & 245 & 570 & & & & & & & 562 \\
\hline SX-101 & 729 & 140 & $\mathrm{BDL}$ & 140 & & & & & \\
\hline $\mathrm{SX}-103$ & 1147 & 850 & 173 & 849 & & & ? & & \\
\hline SX-106 & 650 & 349 & 299 & 354 & & & & & 340 \\
\hline$S Y-101$ & 1546 & 1021 & & & 218 & 181 & & & \\
\hline SY -103 & 316 & 227 & & & 176 & 160 & & & \\
\hline $\mathrm{T}-102^{*}$ & & 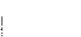 & 86 & & & & & & BDL \\
\hline$\Gamma-107$ & 54 & 74 & 24 & 72 & & $i$ & $i$ & & 32 \\
\hline $1-110$ & 82 & & 58 & & . & & . & . & \\
\hline $\mathrm{T}-111$ & 4 & 13 & 29 & 8 & 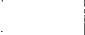 & & . & & \\
\hline TX-101 & 123 & 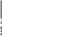 & & 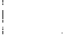 & : & . & & 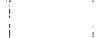 & $\mathrm{BDL}$ \\
\hline TX-102 & 9 & 204 & & & 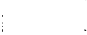 & 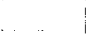 & 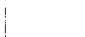 & 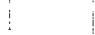 & 172 \\
\hline $\mathrm{TX} \cdot[03$ & 43 & & 102 & & : & & & & 62 \\
\hline $\mathrm{TX} \cdot 104$ & 91 & & $\vdots$ & : & & & & & BDL \\
\hline $\mathrm{rX}-105$ & $\mathrm{BDl}$ & & $\mathrm{BDL}$ & 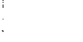 & . & : & i & & $\mathrm{BDL}$ \\
\hline $1 \times-106$ & 4 & & & & & & . & . & BDL \\
\hline TX-107 & BDI. & 4 & $\vdots$ & : & & ' & & & BDL \\
\hline ТX-108 & $\mathrm{BDL}$ & & . & : & & . & & & BDL, \\
\hline $1 X=109$ & BDL & & BDL & & & : & & . & BDL \\
\hline$[X-110$ & BDL & 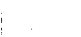 & 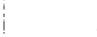 & : & & . & & & BDL. \\
\hline$[\mathrm{X}-111$ & 73 & 179 & $:$ & . & & . & . & $\ldots$ & $\mathrm{BDL}$ \\
\hline TX-1 12 & 167 & 511 & & . & . & . & . & . & $\mathrm{BDL}$ \\
\hline TX-113 & 66 & 242 & & & . & & & & BDL \\
\hline ГX-114 & 42 & & & & . & & & & BDL \\
\hline TX-115 & 140 & 297 & & & & . & 1 & 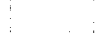 & BDL. \\
\hline $\mathrm{TX}-116$ & BDL & . & ..... & · & 1 & & & & BDL \\
\hline TX-117 & $\mathrm{BDL}$ & & & & & & . & & BDL \\
\hline$[x-1] 8$ & BDL & & 71 & & & 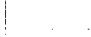 & & & $\mathrm{BDL}$ \\
\hline$\Gamma Y-101$ & 9 & ! & 36 & & 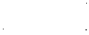 & 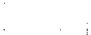 & i & & BDL \\
\hline $\mathrm{TY}-102$ & 26 & 72 & & & $\vdots$ & 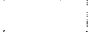 & 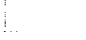 & & 4 \\
\hline TY-103 & $\mathrm{BDI}$. & $\mathrm{BDL}$ & 34 & BDL & & . & & & BDI \\
\hline TY-104* & & & 57 & & & $i$ & & & BDL. \\
\hline l'Y- 105 & 64 & & 51 & & & . & '. & & 5 \\
\hline TY-106* & & & 156 & & & & & & $\mathrm{BDL}$ \\
\hline U. -103 & 177 & 377 & 174 & 369 & 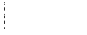 & & 420 & & 359 \\
\hline
\end{tabular}


HNF-3296, Rev. 0

Table 1. Retained Gas Volume Inventory Comparisons (3 Sheets)

\begin{tabular}{|c|c|c|c|c|c|c|c|c|c|}
\hline \multirow{3}{*}{$\begin{array}{r}\text { Tank } \\
(241-)\end{array}$} & \multicolumn{2}{|c|}{$\begin{array}{c}\text { Hodgson } \\
\text { (1996) }\end{array}$} & \multicolumn{2}{|c|}{$\begin{array}{c}\text { Reevaluations } \\
\text { (Appendix) }\end{array}$} & VFI & \multicolumn{3}{|c|}{ RGS } & \multirow{2}{*}{$\begin{array}{l}\text { BPE II } \\
\text { Whitney } 97 \\
\text { (Median } \mathrm{dl} / \mathrm{dp} \text { ) }\end{array}$} \\
\hline & $\begin{array}{c}\text { Surface } \\
\text { Level Rise }\end{array}$ & BPE & $\begin{array}{c}\text { Surface } \\
\text { Level Rise }\end{array}$ & BPE & $\begin{array}{l}\text { Stewart } \\
96\end{array}$ & $\begin{array}{l}\text { Meyer } \\
97^{2}\end{array}$ & $\begin{array}{c}\text { Mahoney } \\
97\end{array}$ & $\left|\begin{array}{c}\text { Shèkarriz } \\
97^{3}\end{array}\right|$ & \\
\hline & $\begin{array}{l}\text { Standard } \\
\text { Voliume } \\
\left(\mathrm{m}^{3}\right)\end{array}$ & $\begin{array}{l}\text { Standard } \\
\text { Volitme } \\
\left(m^{3}\right)\end{array}$ & $\begin{array}{c}\text { Standard } \\
\text { Volume } \\
\left(\mathrm{m}^{3}\right)\end{array}$ & $\left|\begin{array}{c}\text { Standard } \\
\text { Volume } \\
\left(\mathrm{m}^{3}\right)\end{array}\right|$ & $\begin{array}{l}\text { Standard } \\
\text { Volume } \\
\left(\mathrm{m}^{3}\right)\end{array}$ & $\begin{array}{c}\text { Standard } \\
\text { Volume } \\
\left(\mathrm{m}^{\mathrm{l}}\right)\end{array}$ & $\begin{array}{l}\text { Standard } \\
\text { Volume } \\
\left(\mathrm{m}^{3}\right)\end{array}$ & $\begin{array}{c}\text { Standard } \\
\text { Volume } \\
\left(\mathrm{m}^{3}\right)\end{array}$ & $\begin{array}{c}\text { Standard } \\
\text { Volume } \\
\left(m^{3}\right)\end{array}$ \\
\hline U. -105 & 732 & 335 & & & & & & & 261 \\
\hline U-106 & 137 & 78 & 46 & 36 & & & & & 41 \\
\hline $1-107$ & 112 & 235 & & & & & & & 202 \\
\hline$v-100$ & 189 & 278 & & & & & & & 290 \\
\hline
\end{tabular}

BDL $=$ Below detection limit

* Passed the quick screen described in Hodgson (1996).

** Tank 241-AX-10t has been recently sampled using the RGS. This value is placed in the Mahoney 97 column for clarity (data is unpublished; author unknown at this time). Refer to Barker (1998) for a detailed analysis of the authorization basis for this tank.

1 Values are based on VFI data for the non-convective and convective layers plus the associated crust gas volume from Meyer (1997).

2 Values reflect the modeling of combined RGS and VFl data. Data for 241-SY-101 and 241SY -103 are from VFI only.

${ }^{3}$ Values for 241-AN-104,241-AN-105 and 241-AW-101 are based on RGS data for the nonconvective and convective layers plus the associated crust gas volume from Meyer (1997).

\section{ASSUMPTIONS}

Assumptions made during data collection and analysis included:

1) Either of the BPE models can accurately determine the relationship between waste level and barometric pressure changes, thereby yielding a meaningful retained gas volume after subsequent analysis. This assumes that the applicable qualifying conditions for use of the BPE model were met. Meyer (1997) states that the BPE model should not be applied to tanks:

- in which the interstitial liquid level is well below the waste surface;

- with a very low waste level (volume);

- that have been saltwell pumped;

- with a forest of suspended hardware in the waste;

- when a precise waste level instrument is not available or readings are not taken with sufficient frequency; and 
HNF-3296, Rev. 0

- when the tank and instrument geometry is such that the response of the waste level measuring instrument does not reflect waste behavior (when located near the edge of a dry surface saltcake tank, the instrument might not register the behavior of the waste surface near the center of the tank).

No attempt has been made to validate that these conditions are met.

2) When using the SLR model, observed waste surface level changes are due to the accumulation of retained gas in addition to waste evaporation, addition, leakage and subsidence.

3) VFI and RGS data are generally of higher quality than BPE estimations of void fraction.

4) The BPE II model methodology developed is valid for use (associated dl/dp applicable for input into the evaluating spreadsheet).

5) Gas volumes derived from the SLR model are not suitable for direct comparisons (between Hodgson (1996) and the reevaluations found in the electronic spreadsheet summary file) by themselves because there is a high uncertainty associated with them.

\section{CONCLUSIONS}

From the simple analysis of Table 1 one can see (with the exception of tank 241-AX-101) that there are no newly available data that imply that the gas volumes used for the technical basis in the BIO were significantly under estimated such that their facility group would change.

Conversely, (based on the majority of the VFI and RGS measurements) it would appear that Hodgson (1996) was conservative in its estimates of retained gas volume based on the SLR model. Any attempt to estimate the gas volume must include careful analysis of the tank specific conditions and should look at the results of multiple methods of estimating. 
HNF-3296, Rev. 0

\section{REFERENCES}

Barker, S. A., LMHC, to K. M. Hodgson, LMHC, "Response to Potential Inadequacy in the Authorization Basis for Tank 241-AX-101", LMHC-7A140-98-041, dated July 1, 1998.

Hopkins, J. D., 1996, Methodology For Flammable Gas Evaluations, WHC-SD-WM-TI-724, Rev. 1, Westinghouse Hanford Company, Richland, Washington.

Hodgson, K.M., R. P. Anantamula, S. A. Barker, K. D. Fowler, J. D. Hopkins, J. A. Lechelt, D. A. Reynolds, D. C. Hedengren, R. E. Stout, and R. T. Winward, Evaluation of Hanford Tanks for Trapped Gas, WHC-SD-WM-ER-526, Rev. 1c, Westinghouse Hanford Company, Richland, Washington

Leach, C. E., 1997, Tank Waste Remediation System Basis for Interim Operation, HNF-SD-WM-BIO-001, Revision 0-A, DE\&S Hanford, Inc., Richland, Washington.

Mahoney, L. A., Z. I. Antoniak, and J. M. Bates, 1997, Composition and Quantities of Retained Gas Measured in Hanford Waste Tanks 241-U-103, S-106, BY-101, and BY-109, PNNL-11777, Pacific Northwest National Laboratory, Richland, Washington

Meyer, P. A., M. E. Brewster, S. A. Bryan, G. Chen, L. R. Pederson, C. W. Stewart, and G. Terrones, 1997, Gas Retention and Release Behavior in Hanford Double-Shell Waste Tanks, PNNL-11536, Rev 1, Pacific Northwest National Laboratory, Richland, Washington.

Shekarriz, A., D. R. Rector, L.A. Mahoney, M. A. Chieda, J. M. Bates, R. E. Bauer, N. S. Cannon, B. E. Hey, C. G. Linschooten, F. J. Reitz and E. R. Siciliano, 1997, Composition and Quantities of Retained Gas Measured in Hanford Waste Tanks 241-AW-101, 241-A-101, $24 I-A N-105,24 I-A N-104$, and 241-AN-103, PNNL-1 1450, Rev. 1, Pacific Northwest National Laboratory, Richland, Washington.

Stewart, C. W., R. E. Mendoza, J. M. Alzheimer, H. C. Reid, M. E. Brewster, C. L. Shepard, G. Chen, and G. Terrones, 1996, In Situ Rheology and Gas Volume in Hanford Double-Shell Waste Tanks, PNNL-11296, Pacific Northwest National Laboratory, Richland, Washington.

Whitney, P. D., G. Chen, P. A. Gauglitz, P. A. Meyer, and N. E. Miller, 1997, Estimating Retained Gas Volumes in the Hanford Tanks Using Waste Level Measurements, PNNL-1 1693, Pacific Northwest National Laboratory, Richland, Washington 
HNF-3296

no

Appendix

Summary Data for Tanks Reevaluated Using the Methodology of Hopkins 
HNF-3296

new 0

APPENDIX: Summary Data for Tanks Reevaluated Using the Methodology of Hopkins

This appendix contains a table adapted from an electronic spreadsheet summary file maintained by Tank Waste Remediation System (TWRS) Process Engineering that tracks the inputs and results of each tank's flammable gas evaluation using the methodology of Hopkins (1996). The table provides input data and reevaluation results for 32 of 35 tanks that are used for comparison to results as reported in Hodgson (1996). Specific data extracted from this table include the Compressed Volume of Trapped Gas (results from the SLR evaluation - column 93) and the Compressed Volume of Trapped Gas (results from the BPE evaluation - column 104). Other data columns shown are provided as a general reference for the reader. 


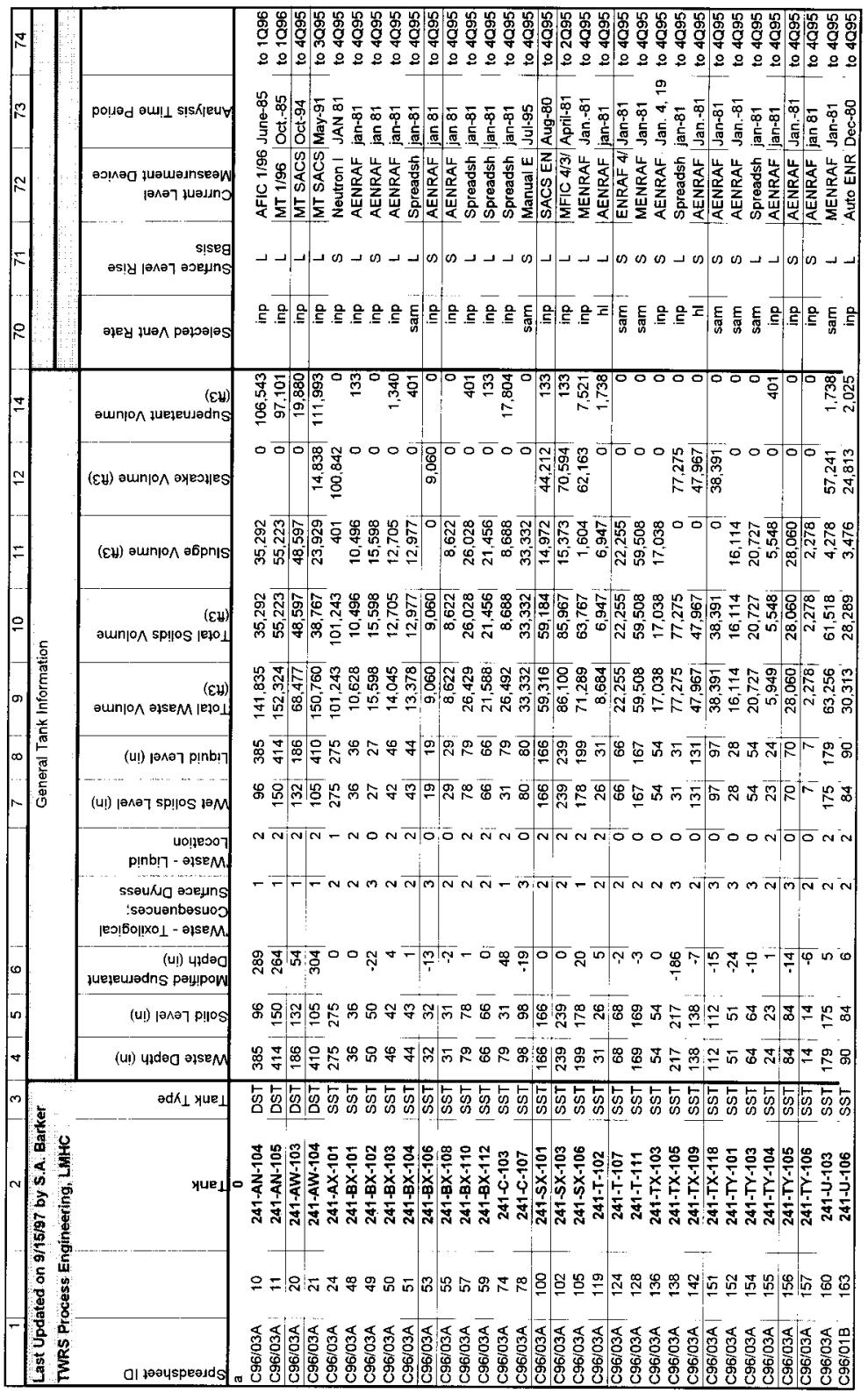


HุNF-3296

neso

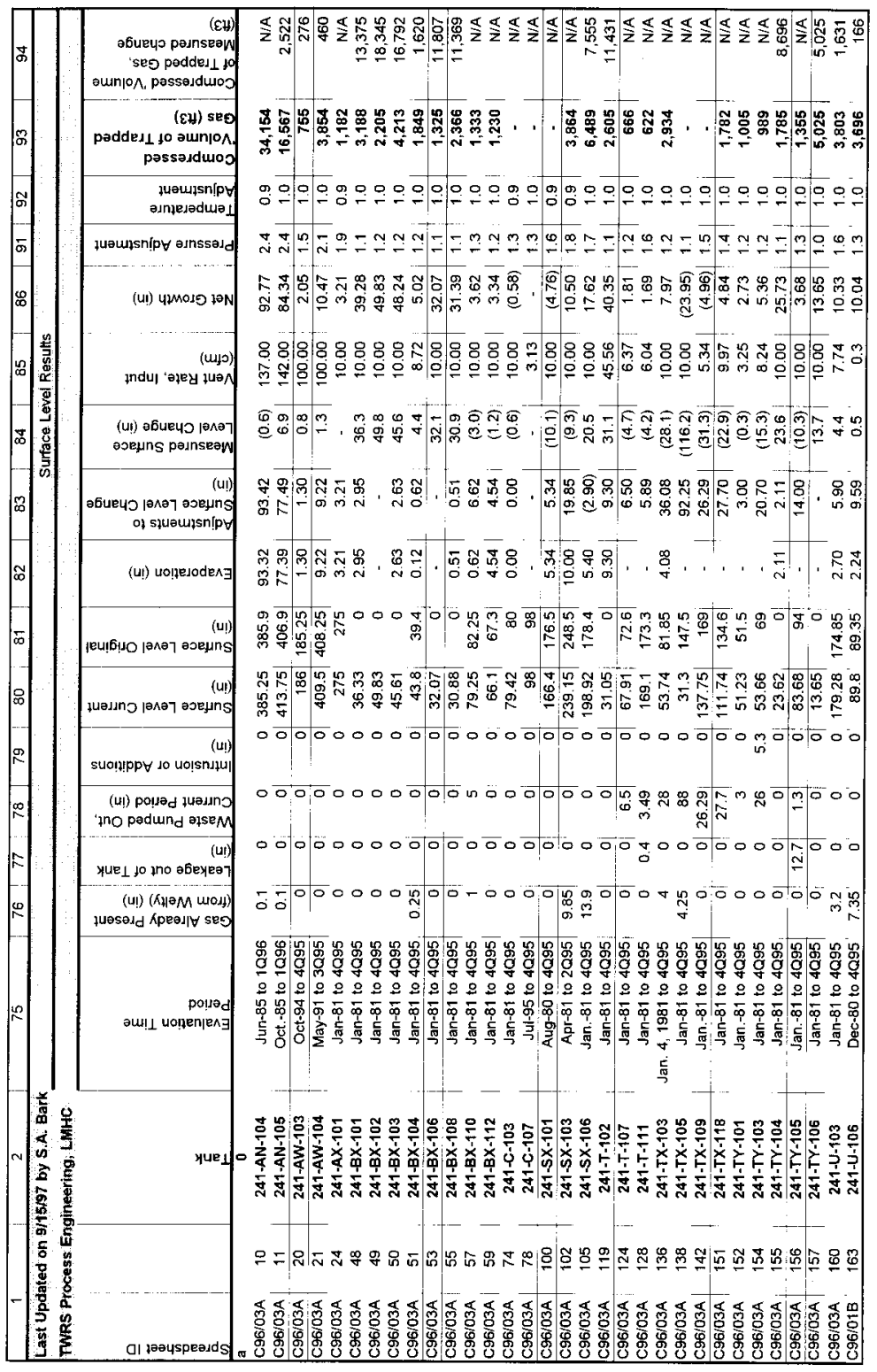




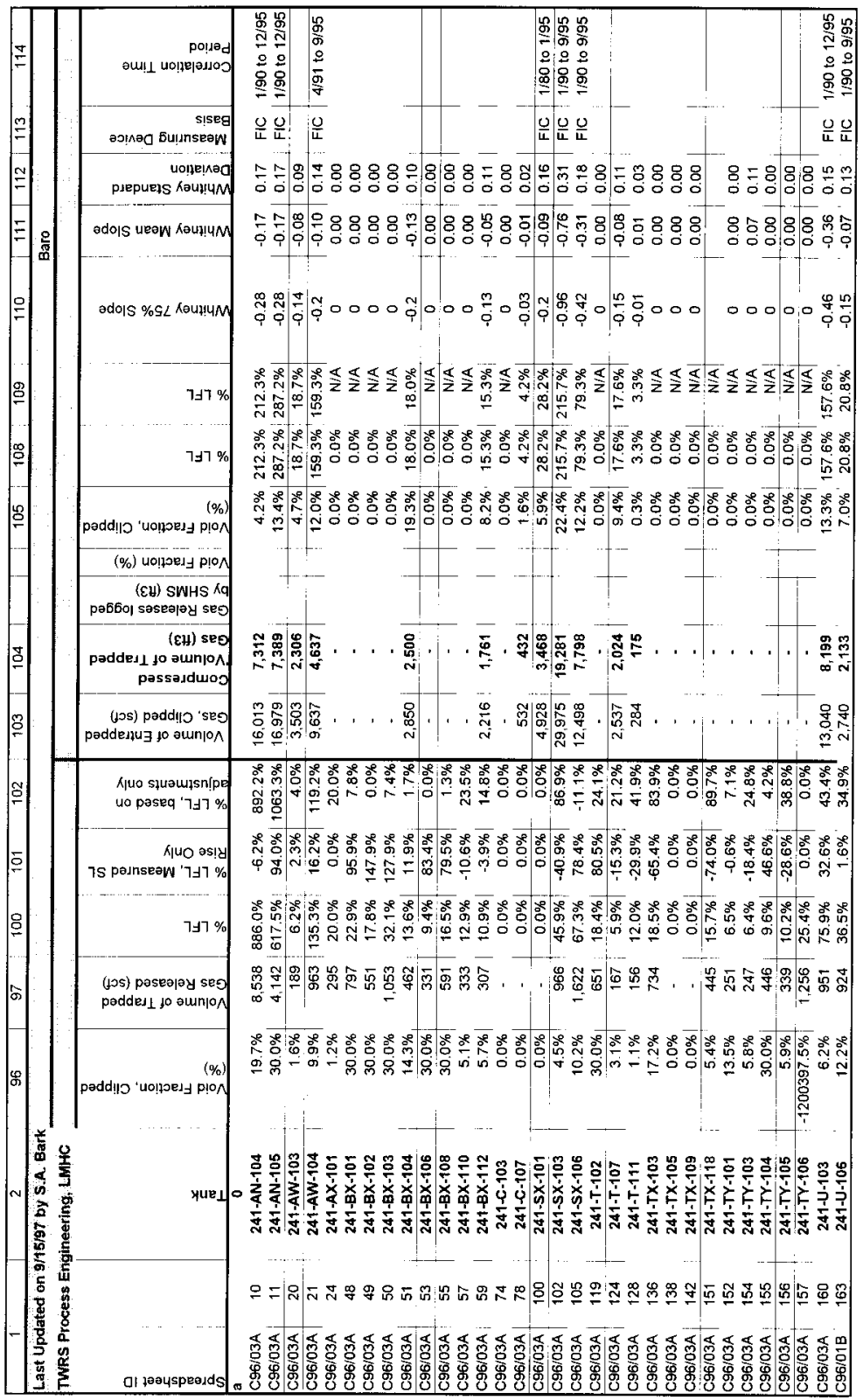




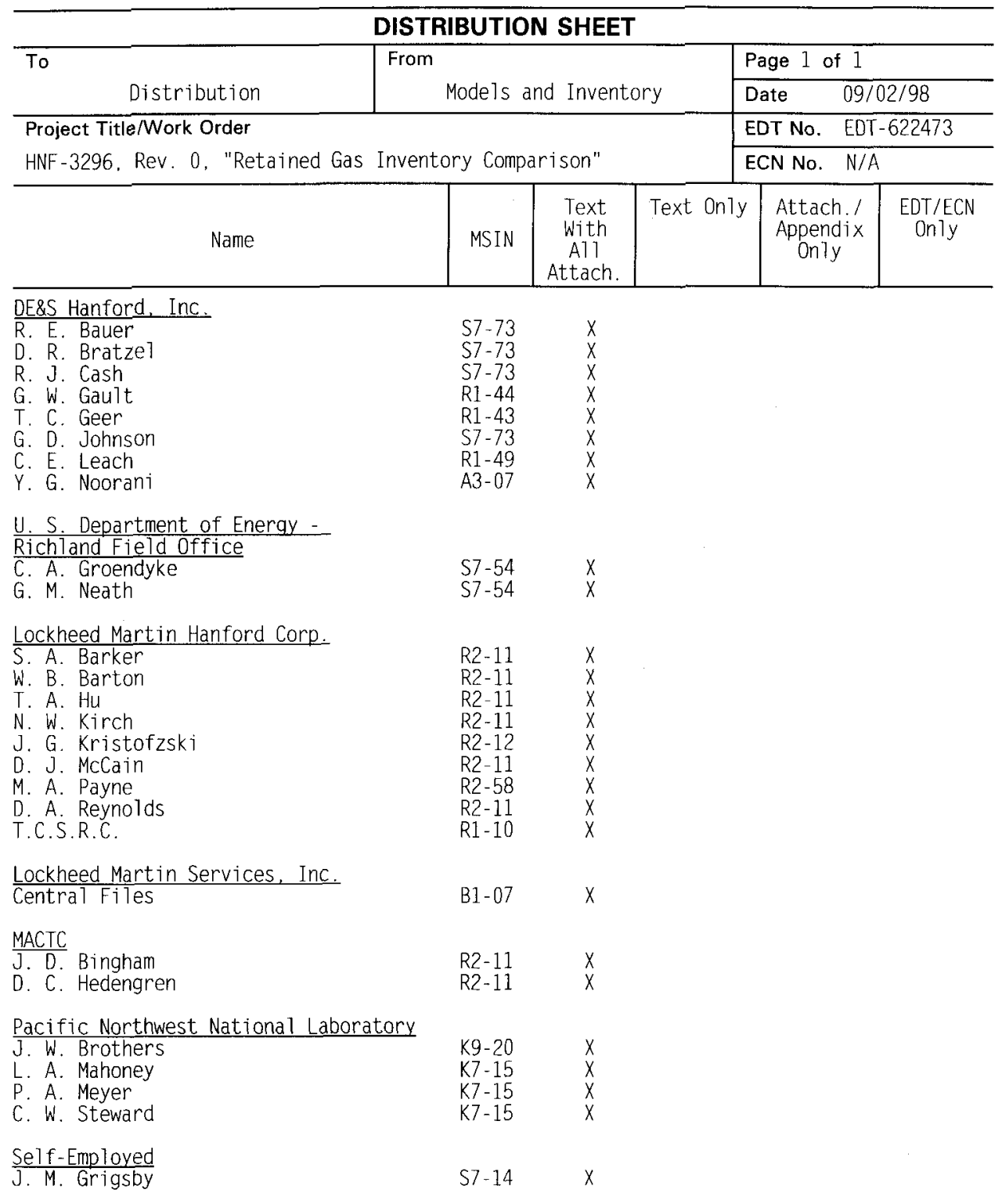

